\title{
Reticular Cell
}

National Cancer Institute

\section{Source}

National Cancer Institute. Reticular Cell. NCI Thesaurus. Code C13057.

A cell with processes making contact with those of other similar cells to form a cellular network sheathing a network of reticular fibers, which constitutes the stroma of all lymphoid organs except the thymus 